\title{
Adult physical, sexual, and emotional abuse and postpartum depression, a population based, prospective study of 53,065 women in the Norwegian Mother and Child Cohort Study
}

\author{
Marie Flem Sørb $\varnothing^{1 *}$, Hilde Grimstad ${ }^{1}$, Johan Håkon Bjørngaard ${ }^{1,2}$, Mirjam Lukasse ${ }^{1,3}$ and Berit Schei ${ }^{1,4}$
}

\begin{abstract}
Background: Postpartum depression (PPD) has detrimental consequences to the women, their infants and families. The aim of the present study was to assess the association between adult abuse and PPD.

Methods: This study was based on data from 53,065 pregnant women in the Norwegian Mother and Child Cohort Study (MoBa), conducted by the Norwegian Institute of Public Health. Women were recruited through a postal invitation in relation to a routine ultra-sound invitation at week 18 of gestation. Exposure to adult emotional, sexual, physical abuse was based on self-report at week 30, also differentiating if the perpetrator was known or a stranger, and whether the abuse was recent or not $(<12$ month since abuse). PPD was measured with a four items version of the Edinburgh Postnatal Depression Scale (EDS) at six months postpartum. The associations between different types of adult abuse and PPD were performed with logistic regression, adjusting for age, parity, civil status, education, child abuse, social support, and depression prior to pregnancy.
\end{abstract}

Results: Altogether, 11\% had PPD, and 19\% had been exposed to adult abuse. Women reporting adult abuse had an $80 \%$ increased fully adjusted odds of PPD (OR $1.895 \%$ Cl 1.7-1.9) compared to non-abused women. There was a tendency towards higher odds of PPD for women reporting combinations of adult abuse (emotional, sexual and physical), as compared with those reporting sexual, emotional or physical abuse only. Exposure from known perpetrator was more strongly associated with PPD than exposure from an unknown perpetrator. Compared with women without adult abuse, the fully adjusted odds of PPD was 2.6 (95\% Cl 2.4-2.9) higher for women with any recent adult abuse and 1.5 (95\% Cl 1.5-1.7) higher for women with any adult abuse, but not recent.

Conclusions: The results from this large prospective population-based cohort study support initiatives aiming to assess and adequately address abuse when counseling and treating women of PPD.

Keywords: Adult Physical, Emotional, Sexual abuse, and recent abuse, Postpartum Depression (PPD), Edinburgh Postnatal Depression Scale (EDS), The Norwegian Mother and Child Cohort Study (MoBa)

\footnotetext{
* Correspondence: marie.flem.sorbo@ntnu.no

'Department of Public Health and General Practice, Faculty of Medicine, Norwegian University of Science and Technology, (NTNU), Postbox 8905, N-7491 Trondheim, Norway

Full list of author information is available at the end of the article
} 


\section{Background}

Postpartum depression (PPD) affects around 13\% of women giving birth, and occurs within one year of childbirth [1,2]. PPD is a public health concern, for which the consequences to the woman and her infant have been well established with both short and long term effects [3]. PPD negatively influences the experiences of motherhood and breastfeeding [4], it may cause impaired bonding with the infant [5], and altered relationship with the partner [6,7]. Furthermore, increased risk of future maternal depressions [8] and adverse psychiatric outcomes in adolescent offspring has been demonstrated [9].

Known risk factors for developing PPD include a history of abuse as a child or an adult and overall $35 \%$ of the women worldwide have experienced partner or nonpartner abuse [10-12]. Several studies show that women reporting lifetime abuse, recent intimate partner abuse, or child abuse are considered more prone to develop PPD than their counterparts [10,13-16]. The combination of abuse and depression is complicated, as both stressors put women at elevated risk for health problems and adverse pregnancy outcomes $[7,17]$. Abuse of women and PPD can be prevented, thus increased knowledge facilitating prevention is important. The associations between abuse and PPD have mostly been studied in cross sectional designs $[18,19]$. For example, in a recent review by Beydoun et al only two of seven studies were prospective [20]; similarly two out of six in Wu et al's metaanalysis had a prospective design [21]. These studies included only small samples and did not take into account other well known risk factors for PPD, such as previous depression and child abuse. We wanted to prospectively explore these associations in a large population, also including several possible confounding factors. Our primary objective was to investigate the association between different types of adult abuse, emotional, sexual and physical, as singular or combined exposures, and PPD. Secondly, we wanted to explore whether the associations differed if the perpetrator was known or a stranger to the woman.

\section{Methods}

\section{Study population}

Our study uses data from the Norwegian Mother and Child Cohort Study (MoBa), a prospective populationbased pregnancy cohort study conducted by the Norwegian Institute of Public Health. The inclusion period was from 1999 to 2008. Hospitals with more than 100 births annually were invited to collaborate in the MoBa study and $70 \%$ of all pregnant women in Norway during this period were invited to participate. A total of 90,700 mothers and 108,000 children agreed to participate in the MoBa study. The response rate was $40.6 \%$. All pregnant women in Norway are offered a routine ultrasound screening at week 18 of gestation at their local hospital
[22]. Together with the ultrasound appointment, the women received a postal invitation that included an informed consent form, the first questionnaire and an information brochure. A detailed protocol of the study including the consent can be found elsewhere (http:// www.fhi.no/morogbarn). Women who agreed to participate received extensive self-administrated questionnaires by post, both during pregnancy and after birth. The MoBa sample has been described in more detail elsewhere [22,23]. Data from the questionnaires are linked to the Medical Birth Registry of Norway, which is based on a standardized form completed by midwives shortly after delivery. The inclusion and exclusion of the study population are shown in Figure 1. Our study population consists of women who had filled in three questionnaires, at 18 and 30 of weeks of gestation, and six months postpartum. For women who participated more than once, information from their first pregnancy was included. Only women with singleton pregnancies and women who had answered a minimum of one of the abuse questions were included in the study. Those having missing on the PPD questions were excluded, leaving a total of 53,065 women whose characteristics are described in Table 1.

A total of 3,864 women were excluded due to missing covariate data, leaving 49,201 women for analyses of the association between different types of adult abuse and symptoms of PPD in Table 2. Of those exposed to adult abuse, 99 women did not report if they knew the perpetrator(s) or not, leaving 49,102 women for analyses in Table 3. Of the women exposed to adult abuse, 186 women did not respond to the questions of recent abuse (last 12 months) or not, leaving 49,015 women for analyses in Table 4. The current study is based on version 4 of the data files released for research in 2008 from the MoBa study. Written informed consent was obtained from each participant at recruitment. The study was approved by The Regional Committee for Medical Research Ethics in South-Eastern Norway. The research was performed in accordance with the Strobe guidelines [24]. An outline of the Strobe guidelines is added in Additional file 1 .

\section{Variables}

\section{Assessment of PPD}

The Edinburgh Postnatal Depression Scale (EDS) is a self-rating scale designed to identify postpartum depression, and has two versions EDS-10 and EDS-5 [25]. The short-matrix 5 items version (EDS-5) has evidence of good psychometric properties, was primarily meant for research use, and has been translated into Norwegian and validated [26]. The questions on PPD were listed in questionnaire 4, and are displayed in Figure 2. In this paper we chose to use the four items identical to the 


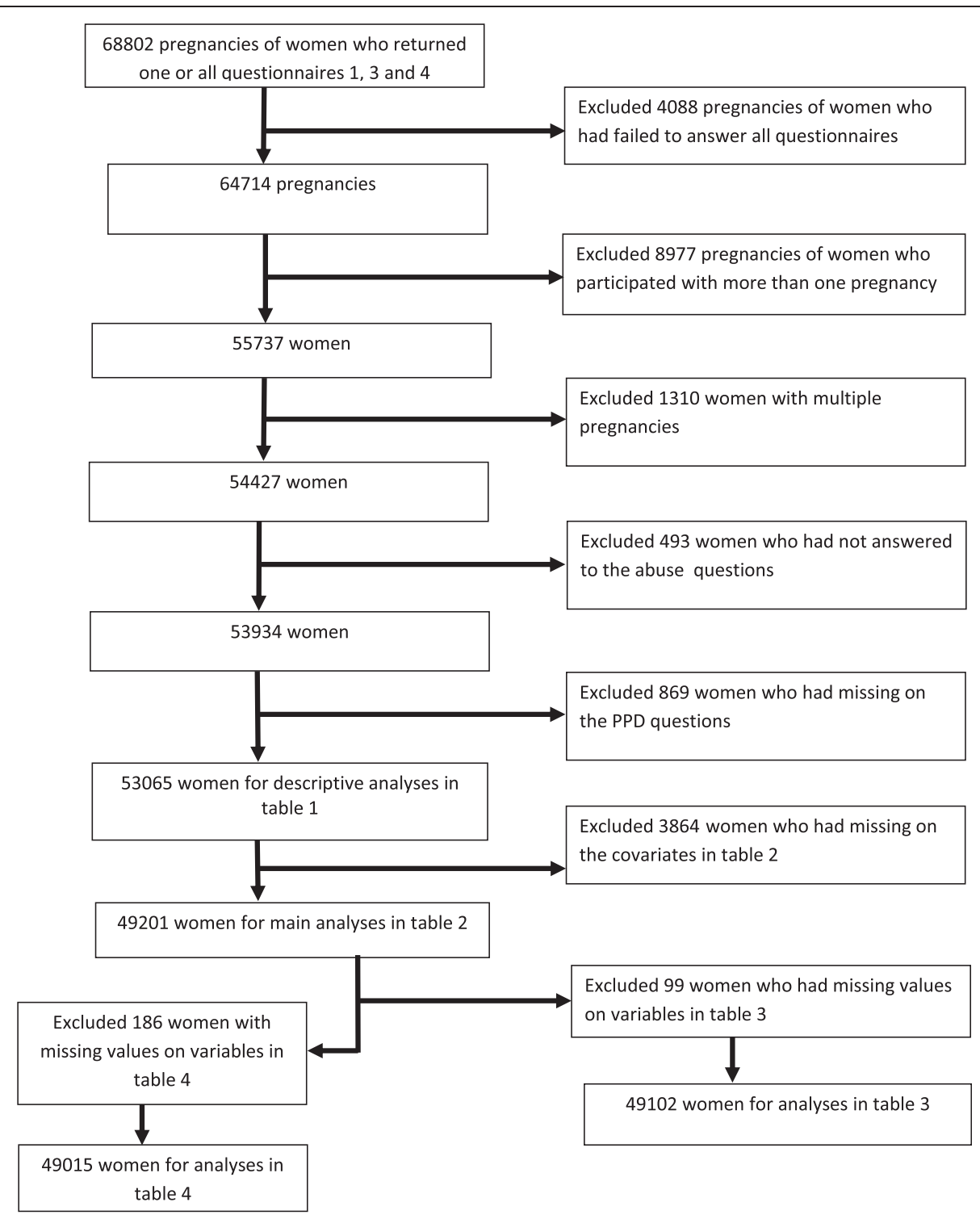

Figure 1 Flow-chart of inclusion.

items in the research version. The score ranges from 0 to 3 on each item, the latter indicating higher depression symptom score. We used a cut off score $\geq 6$ which corresponded with a cut off at $\geq 10$ in the EDS-10, and indicates a moderate level of PPD [27]. The PPD items 1, 2, 4 and 5 in Figure 2 were used in our analyses.

\section{Assessment of abuse}

The abuse questions and response options are shown in Figure 3. These questions were from the third MoBa questionnaire and responded to at approximately week 30 of gestation. The two questions of emotional abuse are almost identical to those in the Norvold Abuse Questionnaire [28], which measures mild and severe emotional abuse. The questions of emotional abuse in our study were merged into one variable. The question on sexual abuse and response options was based on a modified version of the sexual abuse question in the Abuse Assessment Screen (ASS) [29], a screening tool used in other Scandinavian studies [30,31]. The question on physical abuse has been used in other studies, but is not validated [32,33]. Women who answered yes to at least one of the adult abuse questions were defined as having suffered from any adult abuse. Likewise, women responding yes to one or more of the child abuse questions were defined as having suffered from any child abuse (used as a covariate for adjustment). Women could also indicate whether they had been abused the last 12 months or not (in our study categorised as recent abuse or not). 
Table 1 Characteristics of the study population in the Norwegian Mother and Child Cohort Study, 1999-2008

\begin{tabular}{|c|c|c|c|c|}
\hline & \multicolumn{4}{|c|}{ Any adult abuse } \\
\hline & \multicolumn{2}{|c|}{ Yes (10267) } & \multicolumn{2}{|c|}{ No (42798) } \\
\hline & No. & $\%$ & No. & $\%$ \\
\hline \multicolumn{5}{|l|}{ PPD } \\
\hline No & 8370 & 82 & 38979 & 91 \\
\hline Yes & 1897 & 19 & 3819 & 9 \\
\hline${ }^{*} \mathrm{n}$ & 10267 & 100 & 42798 & 100 \\
\hline
\end{tabular}

Age in years

14-19

20-24

25-29

30-34

$\geq 35$

$n$

Education

Primary (9yrs)

Secondary (12yrs)

Higher $\leq 4$ yrs

Higher $>$ 4yrs

Living with partner

Yes
No
n

Parity

0

$1+$

Any child abuse

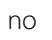

yes

Prior depression

$\begin{array}{lllll}\text { no } & 8928 & 87 & 40795 & 95 \\ \text { yes } & 1339 & 13 & 2003 & 5 \\ n & 10267 & 100 & 42798 & 100\end{array}$

Social support

\begin{tabular}{lllll} 
no & 368 & 4 & 1396 & 3 \\
yes & 9564 & 96 & 39882 & 97 \\
$\mathrm{n}$ & 9932 & 100 & 41278 & 100 \\
\hline
\end{tabular}

${ }^{*} \mathrm{n}$ vary according to numbers of missing values within the different variables. $\mathrm{N}=53,065$.

\section{Perpetrators}

Women were given the opportunity to indicate if the abuse was committed by a stranger, a family member/ relative or other known person (Figure 3). The two latter categories were merged into "known perpetrator". Furthermore, we included women reporting adult abuse from known perpetrator only, in the group; "known only". Those reporting abuse from stranger only were included in "stranger only" and, finally, women reporting abuse from both stranger and known perpetrators were included in the "stranger and known perpetrator" group.

\section{Possible confounding variables}

Background information such as age, education, depression prior to pregnancy, social support, and civil status was collected from the first questionnaire at inclusion, in order to take into account possible confounding factors of the abuse-PPD association. Age was categorized into five groups (Table 1). Information about education was categorized into four groups: primary school (9 years), secondary school (12 years), two groups at college or university level, ( $\leq 4$ years) or ( $>4$ years). Women were asked to respond yes or no to whether, earlier in life, they had suffered from depression in a period of two weeks or more. Social support was defined as having anyone other than the partner the woman can ask for advice in a difficult situation, with three answering options; no, yes 1-2 persons, or yes, more than 2 persons, which we categorized into no or yes. Civil status was defined as living with partner or not. Information about parity was categorized into nulliparous, and women giving birth previous to this pregnancy (1+).

\section{Statistical analyses}

Descriptive statistics of women exposed to adult abuse are presented in Table 1. Logistic regression analyses were used to estimate the associations between different types of adult abuse and PPD (Table 2), to estimate associations between perpetrators (known or unknown) of adult abuse and PPD (Table 3) and, finally, to estimate associations between time of abuse (recent or not) and symptoms of PPD (Table 4). We used three models adjusting for possible confounding factors. In Model 1, we adjusted for age and parity. In Model 2, we adjusted for age, parity, education, civil status, and any child abuse. Finally, in Model 3 all variables from Model 2 were included along with depression prior to pregnancy and experience of social support. The reference group for all analyses was women reporting no adult abuse. Adjusted odds ratios (OR's) were presented for the different models with 95\% confidence intervals (95\% CIs) and analysed for complete cases only. The data programme PASW statistical 20 was used to conduct all analyses. 
Table 2 Logistic regression analyses of the association between types of adult abuse and postpartum depression

\begin{tabular}{|c|c|c|c|c|c|c|c|}
\hline & & \multicolumn{2}{|c|}{ Model 1} & \multicolumn{2}{|c|}{ Model 2} & \multicolumn{2}{|c|}{ Model 3} \\
\hline & & OR & $95 \% \mathrm{Cl}$ & OR & $95 \% \mathrm{Cl}$ & OR & $95 \% \mathrm{Cl}$ \\
\hline & n_PPD & & & & & & \\
\hline No adult abuse (ref) & 3471 & 1.0 & & 1.0 & & 1.0 & \\
\hline Physical only & 75 & 1.7 & $(1.4-2.2)$ & 1.5 & $(1.1-1.9)$ & 1.4 & $(1.1-1.8)$ \\
\hline Sexual only & 149 & 2.0 & $(1.7-2.4)$ & 1.7 & $(1.4-2.1)$ & 1.6 & $(1.4-2.0)$ \\
\hline Emotional only & 888 & 2.1 & $(2.0-2.3)$ & 1.8 & $(1.7-2.0)$ & 1.7 & $(1.6-1.9)$ \\
\hline Emot.-physical & 229 & 2.8 & $(2.4-3.2)$ & 2.2 & $(1.9-2.6)$ & 2.0 & $(1.7-2.3)$ \\
\hline Physical-sexual & 33 & 2.2 & $(1.5-3.2)$ & 1.8 & $(1.2-2.6)$ & 1.7 & $(1.2-2.5)$ \\
\hline Emot.-sexual & 156 & 3.6 & $(3.0-4.4)$ & 2.9 & $(2.4-3.5)$ & 2.3 & $(1.9-2.8)$ \\
\hline Emot.-physic.-sex. & 195 & 3.4 & $(2.9-4.0)$ & 2.7 & $(2.3-3.2)$ & 2.2 & $(1.9-2.6)$ \\
\hline Any adult abuse & 1725 & 2.4 & $(2.2-2.5)$ & 2.0 & $(1.8-2.1)$ & 1.8 & $(1.7-1.9)$ \\
\hline
\end{tabular}

Model 1 adjusted for age and parity. Model 2 adjusted for age, parity, civil status, child abuse, education. Model 3 adjusted for age, parity, civil status, child abuse, education, social support, and prior depression. *Numbers of women in each abuse category reporting PPD. Analyzed for complete cases on all variables. $\mathrm{N}=49,201$.

\section{Results}

Altogether, 11\% of the women had PPD and 6\% reported depression prior to pregnancy. Nineteen percent reported exposure to any adult abuse. Table 1 presents characteristics for the study participants by exposure to any adult abuse or not. Figure 4 shows the number of women reporting different types of adult abuse and combinations of adult abuse. Among the 2,938 women reporting adult physical abuse, 593 reported having suffered from adult physical abuse only. Of the 8,601 women reporting adult emotional abuse, 5,792 did not report having experienced any other abuse. While among those 2,816 reporting adult sexual abuse, 1,033 women reported adult sexual abuse only. Women reporting any adult abuse had an $80 \%$ increased fully adjusted odds of PPD symptoms (OR 1.8, 95\% CI 1.71.9) compared to women without any adult abuse (Table 2 ). Women reporting combinations of emotional, physical and sexual abuse were more at risk of PPD than women reporting only one type of abuse. Women reporting three types of abuse; emotional, physical and sexual abuse, had a $120 \%$ increased fully adjusted odds of PPD (OR 2.2, 95\% CI 1.92.6) compared to women reporting no adult abuse. Compared with women with no adult abuse, exposure from known perpetrator was more strongly associated with PPD than exposure from an unknown perpetrator (fully adjusted OR known perpetrator only 1.8, 95\% CI 1.7-1.9 and unknown and known perpetrators OR 2.0, 95\% CI 1.7-2.4 versus OR unknown perpetrator only 1.5 , 95\% CI 1.2-1.9) (Table 3). The odds ratio of PPD symptoms following any recent abuse in the fully adjusted model was 2.6 (95\% CI 2.4-2.9) compared to no adult abuse, while those women reporting no recent abuse had an OR of 1.6 (95\% CI 1.51.7) (Table 4). The associations between all types of adult abuse and PPD were attenuated when adjusted for confounding factors introduced in Models 2 and 3.

\section{Discussion}

All types of adult abuse were strongly associated to PPD. Although the associations were attenuated with adjustment for possible confounding factors such as age,

Table 3 Logistic regression analyses of the association between perpetrator status (known/unknown) and postpartum depression

\begin{tabular}{|c|c|c|c|c|c|c|c|}
\hline \multirow{2}{*}{\multicolumn{2}{|c|}{ Perpetrator + any adult abuse }} & \multicolumn{2}{|c|}{ Model 1} & \multicolumn{2}{|c|}{ Model 2} & \multicolumn{2}{|c|}{ Model 3} \\
\hline & & OR & $95 \% \mathrm{Cl}$ & OR & $95 \% \mathrm{Cl}$ & OR & $95 \% \mathrm{Cl}$ \\
\hline & \multicolumn{7}{|c|}{ n_PPD* } \\
\hline No adult abuse (ref) & 3471 & \multicolumn{2}{|l|}{1.0} & \multicolumn{2}{|l|}{1.0} & \multicolumn{2}{|l|}{1.0} \\
\hline Known only & 1353 & 2.3 & $(2.1-2.5)$ & 2.0 & $(1.8-2.1)$ & 1.8 & $(1.7-1.9)$ \\
\hline Unknown only & 102 & 1.5 & $(1.2-1.9)$ & 1.6 & $(1.3-2.0)$ & 1.5 & $(1.2-1.9)$ \\
\hline Unknown and known & 254 & 3.7 & $(3.2-4.3)$ & 2.3 & $(1.9-2.6)$ & 2.0 & $(1.7-2.4)$ \\
\hline
\end{tabular}

Model 1 adjusted for age and parity. Model 2 adjusted for age, parity, civil status, education, and child abuse. Model 3 adjusted for age, parity, civil status, education, child abuse, social support, and prior depression. *Numbers of women reporting PPD within each category of perpetrator/abuse. Analyzed for complete cases only, $\mathrm{N}=49,102$. 
Table 4 Logistic regression analyses of the association between time (recent/not recent) of adult abuse and postpartum depression

\begin{tabular}{|c|c|c|c|c|c|c|c|}
\hline & & \multicolumn{2}{|c|}{ Model 1} & \multicolumn{2}{|c|}{ Model 2} & \multicolumn{2}{|c|}{ Model 3} \\
\hline & & OR & $95 \% \mathrm{Cl}$ & OR & $95 \% \mathrm{Cl}$ & OR & $95 \% \mathrm{Cl}$ \\
\hline & n_PPD & & & & & & \\
\hline No adult abuse (ref) & 3471 & 1.0 & & 1.0 & & 1.0 & \\
\hline Any adult abuse, but not recent & 1160 & 2.0 & $(1.9-2.2)$ & 1.7 & $(1.6-1.9)$ & 1.6 & $(1.5-1.7)$ \\
\hline Any adult recent abuse & 527 & 3.6 & $(3.2-4.0)$ & 2.9 & $(2.6-3.2)$ & 2.6 & $(2.4-2.9)$ \\
\hline
\end{tabular}

Model 1 adjusted for age and parity. Model 2 adjusted for age, parity, civil status, child abuse, education. Model 3 adjusted for age, parity, civil status, child abuse, education, social support, and prior depression. *Numbers of women in abuse categories reporting PPD. Analyzed for complete cases on all variables, $\mathrm{N}=49,015$.

parity, child abuse, civil status, education, social support and depression prior to the pregnancy, the substantial associations remained in the fully adjusted models.

\section{Strengths and limitations}

The prospective design of the study is a major strength. Also, the study included a large number of non- selected groups of pregnant women. The reporting of abuse and potential confounding factors were assessed during pregnancy hence reported prior to and unrelated to the reporting of PPD. We were also able to adjust for known risk factors of PPD, like child abuse, experience of social support, and previous depression, which is not always included in previous studies. There are also limitations. We were able to use only four out of five items in the validated EDS-5 version (research version) to measure PPD [27]. This may have influenced our estimated prevalence, but is probably less likely to have influenced our estimated associations. Also, diagnostic information of PPD would have been an advantage. However, given the prospective design of our study where potential confounding information was reported early in pregnancy and outcome assessment of PPD was reported after pregnancy, we believe that misclassification of abuse is not likely to be differential. The low response rate in the MoBa survey of $40.6 \%$ is a limitation. Nevertheless, a study investigating the possible effect of the low response rate on eight well-known exposureoutcome factors in the MoBa survey, concluded that prevalence estimates of exposures and outcomes were biased, but not estimates of associations between exposure and outcome [22].

\section{Comparing the results to other studies Prevalence}

Our results of PPD at $11 \%$ are in the range of the prevalence found in other studies in high income countries; including one Norwegian study using EPD-10 where 9\% had PPD [34] and a meta-analysis where the prevalence of PPD was $13 \%$ [1].

\section{Dose-response association}

Overall, women in our study exposed to more than one type of abuse had about a two to three fold increase in PPD, compared to non-abused women. Furthermore, the results indicate a dose-response association, as exposure to more than one type of abuse showed stronger associations to PPD than exposure to one type only. This is in agreement with other studies, where the strength of association increased with each additional type of violence experienced and with increased frequency of abusive acts $[35,36]$.

\section{Type, and timing of the abuse}

Emotional abuse was the most commonly reported type of abuse in our study. Women exposed to emotional abuse only in our study had a slightly higher risk of PPD, compared with women exposed to either only sexual or only physical abuse. This is in accordance with other studies

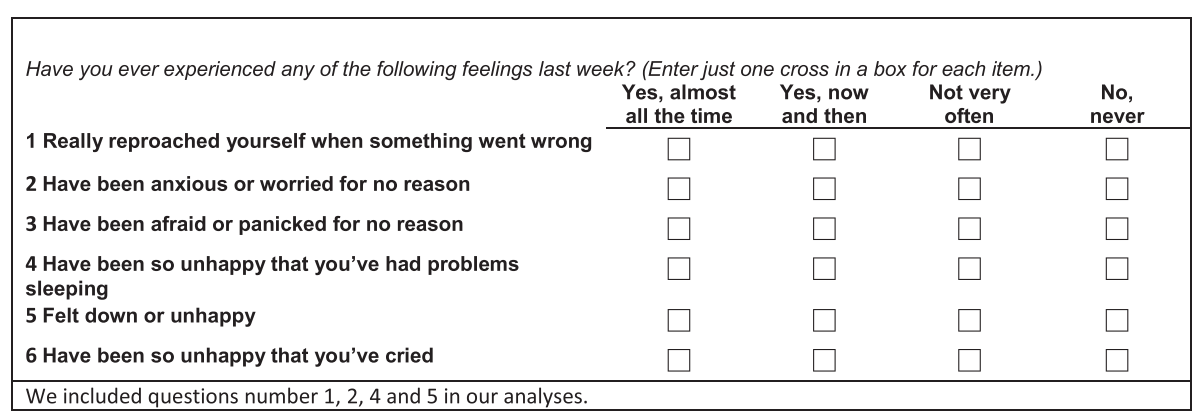

Figure 2 Questions on Postpartum Depression in the Mother and Child Cohort Study. 


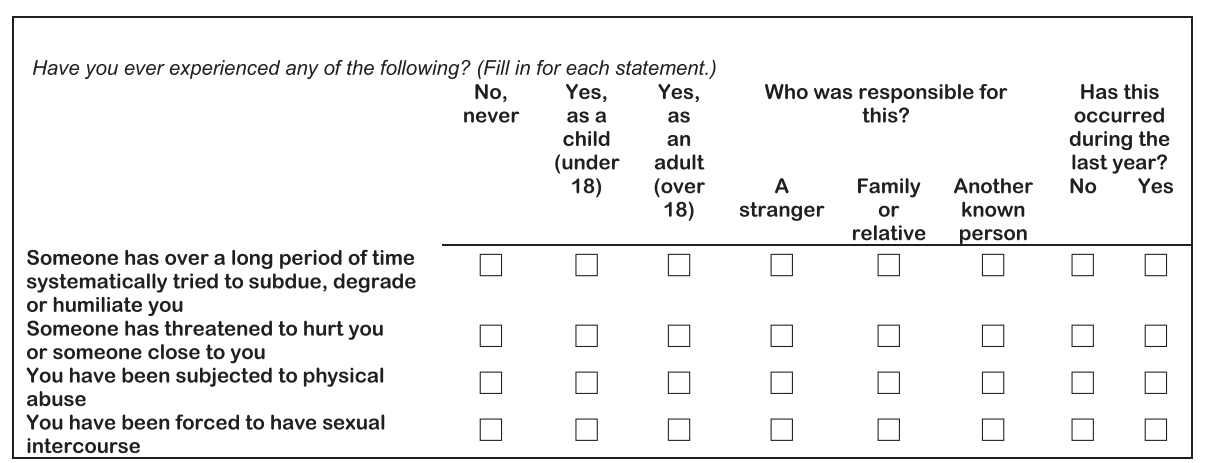

Figure 3 Questions and response options on abuse and perpetrators in the Norwegian Mother and Child Cohort Study.

which indicate a higher risk of PPD among women exposed to emotional abuse compared to other types of abuse. For example, one clinical study of 200 women in Canada showed that emotional abuse but not physical or sexual abuse was found to be associated to PPD [18]. In our study the association between any abuse and PPD was stronger when the abuse was reported as recent compared to past experience. Our findings are consistent with previous studies linking recent abuse to PPD [14,36,37].

\section{Perpetrators}

The literature is both scarce and inconclusive on the topic of perpetrators other than intimate partner. In our study women abused by known perpetrator only, or by known and stranger, were at higher risk of experiencing PPD than those abused by stranger only. This may be because exposure to abusive acts from a known person may have more detrimental effects to the women compared to abuse from a stranger. Reporting exposure of abuse from different perpetrators (both stranger and known) can imply strong association to PPD through different mechanisms.
Being abused by a trusted person is likely to be more detrimental than being abused by an unknown person. Another possible explanation is that exposure to both known and stranger indicating more than one insult; hence contributing to the strong association. Recent studies indicate that recurrent acts of abuse are associated with an increased risk of PPD [36,38], which correspond with our findings according exposure to abuse from different perpetrators. Nevertheless, results from three Canadian studies on PPD comparing abuse by partner and other perpetrators show diverse results $[36,39,40]$. In a population-based survey there was a strong association between abuse by partner and PPD, but no association was found of abusive acts perpetrated by other persons [36]. In contrast, one study showed no differences between women with and without PPD regarding who perpetrated the abuse (partner, other family member, or stranger) [39]. However, in the third study the odds of PPD were significantly greater among women abused by partner compared with those who did not experience partner abuse [40]. In the same study the perpetrators were equally to be partner or non-partner, and

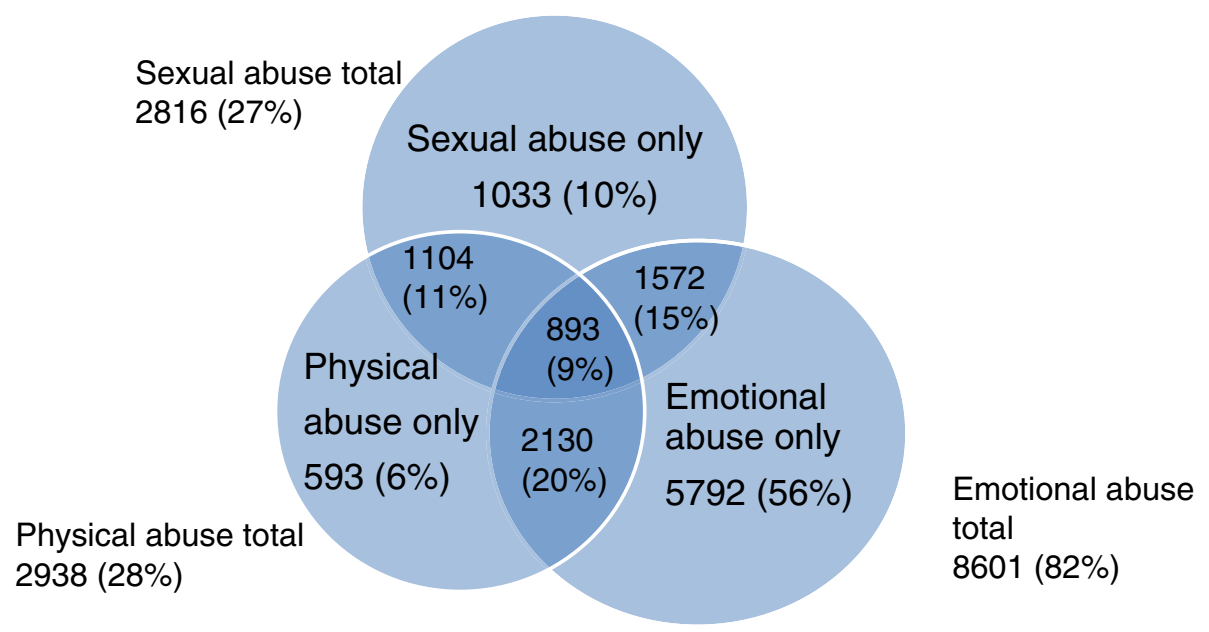

Percentages are calculated from the10,267 women who reported any adult abuse.

Figure 4 Types of adult abuse and overlapping categories. 
although not significant, abuse from other persons (family member, stranger or acquaintance), also showed a positive association to PPD.

\section{Conclusions}

The women in our study commonly reported adult emotional, sexual, and physical abuse. All types were highly associated with PPD, either as singular types of abuse only, or in combination with other types. Furthermore, our findings showed that reporting abuse by a known perpetrator only, or by both a known and a stranger, showed stronger association with PPD compared to those abused from strangers only. Our findings highlight the importance of assessing and adequately addressing abuse when counseling and treating women with PPD.

\section{Additional file}

Additional file 1: STROBE guidelines.

\section{Abbreviations}

(PPD): Postpartum depression; (MoBa): The Norwegian Mother and Child Cohort Study; (PPD): Postpartum depression; (EDS): The Edinburgh Postnatal Depression Scale; (ASS): Abuse assessment screen.

\section{Competing interests}

The authors declare that they have no competing intersts.

\section{Authors' contribution}

MFS prepared the data, performed the statistical analyses, and drafted and corrected the manuscript. HG contributed to the interpretation of the analyses, drafted and critically revised the manuscript. JHB advised on the statistical analyses and the interpretation of the results and critically revised the manuscript. ML contributed to the interpretation of the analyses, drafted and critically revised the manuscript. BS conceived the study idea and planned the study and contributed to the interpretation of the analyses and critically revised the manuscript. All authors contributed to the study's design and read and approved the final manuscript.

\section{Acknowledgements}

The Norwegian Mother and Child Cohort Study is supported by the Norwegian Ministry of Health and the Ministry of Education and Research, NIH/NIEHS (contract no NO1-ES-75558), NIH/NINDS (grant no. 1 UO1 NS 047537-01 and grant no. 2 UI1 NS 047537-06A1). We are grateful to all the participating families in Norway who take part in this on-going cohort study.

\section{Author details \\ ${ }^{1}$ Department of Public Health and General Practice, Faculty of Medicine, Norwegian University of Science and Technology, (NTNU), Postbox 8905, N-7491 Trondheim, Norway. 'Forensic Department and Research Centre, St. Olavs University Hospital Trondheim, Brøset, Norway. ${ }^{3}$ Department of Health, Nutrition and Management, Faculty of Health Sciences, Oslo and Akershus University College of Applied Sciences, St. Olavs plass, Postbox 4 Alnabru, N-0130 Oslo, Norway. ${ }^{4}$ Department of Gynecology, St. Olavs University Hospital, Trondheim, Postbox 3250 Sluppen, N-7006 Trondheim, Norway.}

Received: 28 April 2014 Accepted: 27 August 2014

Published: 8 September 2014

\section{References}

1. O'Hara MW, Swain AM: Rates and risk of postpartum depression-a meta-analysis. Int J Psychiatr 1996, 8:37-54.

2. O'Hara MW: Postpartum depression: what we know. J Clin Psychol 2009, 65(12):1258-1269.
3. Almond P: Postnatal depression: a global public health perspective. Perspect Public Health 2009, 129(5):221-227.

4. Seimyr L, Edburgh M, Lundh W, Sjogren B: In the shadow of maternal depressed mood: Experiences of parenthood during the first year after childbirth. J Psychosom Obstet Gynaecol 2004, 25(1):23-34.

5. Milgrom J, Ericksen J, McCarthy R, Gemmill AW: Stressful impact of depression on early mother-infant relations. Stress Health 2006, 22(4):229-238.

6. Goodman JH: Paternal postpartum depression, its relationship to maternal postpartum depression, and implications for family health. J Adv Nurs 2004, 45(1):26-35.

7. Lee DTS, Chung TKH: Postnatal depression: an update. Best Practice Res Clin Obstet Gynaecol 2007, 21(2):183-191.

8. Meltzer-Brody S: New insights into perinatal depression: pathogenesis and treatment during pregnancy and postpartum. Dialogues Clin Neurosci 2011, 13(1):89-100.

9. Halligan SL, Murray L, Martins C, Cooper PJ: Maternal depression and psychiatric outcomes in adolescent offspring: A 13-year longitudinal study. J Affect Disord 2007, 97(1-3):145-154.

10. WHO, the London School of Hygiene and Tropical Medicine and the Sourth African Medical Research Counci: WHO report highlights violence against women as a 'global health problem of epidemic proportions' New clinical and policy guidelines launched to guide health sector response. In WHO Media Release. 2013. http://www.who.int/mediacentre/news/ releases/2013/violence_against_women_20130620/en/index.html.

11. Neroien Al, Schei B: Partner violence and health: results from the first national study on violence against women in Norway. Scand J Public Health 2008, 36(2):161-168.

12. Campbell JC: Health consequences of intimate partner violence. Lancet 2002, 359(9314):1331-1336.

13. Records K, Rice MJ: Lifetime physical and sexual abuse and the risk for depression symptoms in the first 8 months after birth. J Psychosom Obstet Gynaecol 2009, 30(3):181-190.

14. Valentine JM, Rodriguez MA, Lapeyrouse LM, Zhang M: Recent intimate partner violence as a prenatal predictor of maternal depression in the first year postpartum among Latinas. Arch Womens Ment Health 2011, 14(2):135-143.

15. Buist A: Childhood abuse, parenting and postpartum depression. Aust N Z J Psychiatry 1998, 32(4):479-487.

16. Malta LA, MCDonald SW, Hegadoren KM, Weller CA, Tough SC: Influence of interpersonal violence on maternal anxiety, depression, stress and parenting morale in the early postpartum: a community based pregnancy cohort study. BMC Pregnancy Childbirth 2012, 12:153.

17. Ellsberg M, Jansen HA, Heise L, Watts CH, Garcia Moreno C: Intimate partner violence and women's physical and mental health in the WHO multi-country study on women's health and domestic violence: an observational study. Lancet 2008, 371(9619):1165-1172.

18. Cohen MM, Schei B: A history of personal violence and postpartum depression: is there a link? Arch Womens Ment Health 2002, 4:83-92.

19. Leung WC, Kung F, Lam J, Leung TW, Ho PC: Domestic violence and postnatal depression in a Chinese community. Int J Gynecol Obstet 2002, 79(2):159-166.

20. Beydoun HA, Beydoun MA, Kaufman JS, Lo B, Zonderman AB: Intimate partner violence against adult women and its association with major depressive disorder, depressive symptoms and postpartum depression: a systematic review and meta-analysis. Soc Sci Med 2012, 75(6):959-975.

21. Wu Q, Chen HL, Xu XJ: Violence as a risk factor for postpartum depression in mothers: a meta-analysis. Arch Womens Ment Health 2012, 15(2):107-114.

22. Nilsen RM, Vollset SE, Gjessing HK: Self-selection and bias in a large prospective pregnancy cohort in Norway. Paediatr Perinat Epidemiol 2009 23(6):597-608.

23. Magnus P, Irgens LM, Haug K, Nystad W, Skjaerven R, Stoltenberg C: Cohort profile: the Norwegian Mother and Child Cohort Study (MoBa). Int J Epidemiol 2006, 35(5):1146-1150.

24. Elm E, Douglas G, Altman C, Egger M, Pocock SJ, Gøtzsche PC, Vanderbroucke JP: The strengthening the Reporting of Observational Studies in Epidemiology (STROBE) statement: guidelines for reporting observational studies. J Clin epidemiol 2008, 61(4):344-9.

25. Cox JL, Holden JM, Sagovsky R: Detection of postnatal depression. Development of the 10-item edinburgh postnatal depression scale. Br J Psychiatry 1987, 150:782-786. 
26. Eberhard-Gran M, Eskild A, Tambs K, Schei B, Opjordsmoen S: The edinburgh postnatal depression scale: validation in a norwegian community sample. Nord J Psychiatry 2001, 55(2):113-117.

27. Eberhard-Gran M, Eskild A, Samuelsen SO, Tambs K: A short matrix-version of the edinburgh depression scale. Acta Psychiatr Scand 2007, 116(3):195-200.

28. Swahnberg IM, Wijma B: The NorVold Abuse Questionnaire (NorAQ): validation of new measures of emotional, physical, and sexual abuse, and abuse in the health care system among women. Eur J Public Health 2003, 13(4):361-366.

29. Rabin RF, Jennings JM, Campbell JC, Bair-Merritt MH: Intimate partner violence screening tools: a systematic review. Am J Prev Med 2009, 36(5):439-445.

30. Stenson K, Heimer G, Lundh C, Nordstrom ML, Saarinen H, Wenker A: Lifetime prevalence of sexual abuse in a Swedish pregnant population. Acta Obstet Gynecol Scand 2003, 82(6):529-536.

31. Johnson JK, Haider F, Ellis K, Hay DM, Lindow SW: The prevalence of domestic violence in pregnant women. Bjog-an Int J Obstet Gynaecol 2003, 110(3):272-275.

32. Sorbo MF, Grimstad H, Bjorngaard JH, Schei B, Lukasse M: Prevalence of sexual, physical and emotional abuse in the Norwegian mother and child cohort study. BMC Public Health 2013, 13:186.

33. Lukasse M, Schei B, Vangen S, Oian P: Childhood abuse and common complaints in pregnancy. Birth 2009, 36(3):190-199.

34. Eberhard-Gran M, Eskild A, Tambs K, Samuelsen KO, Opjordsmoen S: Depression in postpartum and non-postpartum women: prevalence and risk factors. Acta Psychiatr Scand 2002, 106(6):426.

35. Garabedian M, Lain KY, Hansen WF, Garcia LS, Williams CM, Crofford LJ: Violence against women and postpartum depression. J Women's Health 2011, 20(3):47-453.

36. Urquia ML, O'Campo PJ, Heaman MI, Janssen PA, Thiessen KR: Experiences of violence before and during pregnancy and adverse pregnancy outcomes: an analysis of the Canadian Maternity Experiences Survey. BMC Pregnancy Childbirth 2011, 11:42.

37. Ross LE, Dennis CL: The prevalence of postpartum depression among women with substance use, an abuse history, or chronic illness: a systematic review. J Womens Health 2009, 18(4):475-486.

38. Janssen PA, Heaman MI, Urquia ML, O'Campo PJ, Thiessen KR: Risk factors for postpartum depression among abused and nonabused women. Am J Obstet Gynecol 2012, 207(6):481-489.

39. Dennis C: Epidemiology of postpartum depressive symptoms among canadian women: regional and national results from a cross-sectional survey. Can J Psychiatr 2012, 57(9):537-546.

40. Beydoun HA, Al-Sahab B, Beydoun MA, Tamim H: Intimate partner violence as a risk factor for postpartum depression among Canadian women in the Maternity Experience Survey. Ann Epidemiol 2010, 20(8):575-583.

doi:10.1186/1471-2393-14-316

Cite this article as: Sørbø et al:: Adult physical, sexual, and emotional abuse and postpartum depression, a population based, prospective study of 53,065 women in the Norwegian Mother and Child Cohort Study. BMC Pregnancy and Childbirth 2014 14:316.

\section{Submit your next manuscript to BioMed Central and take full advantage of:}

- Convenient online submission

- Thorough peer review

- No space constraints or color figure charges

- Immediate publication on acceptance

- Inclusion in PubMed, CAS, Scopus and Google Scholar

- Research which is freely available for redistribution

Submit your manuscript at www.biomedcentral.com/submit
Ciomed Central 